\title{
GCU
}

Glasgow Caledonian

University

University for the Common Good

\section{A validation of web-based surveys for exploratory research in the areas of business and entrepreneurship}

Stouraitis, Vasilios; Mior Harris, Mior Harun; Kyritsis, Markos; Boonchoo, Pattana

Published in:

2018 Fifth HCT Information Technology Trends (ITT)

DOI:

10.1109/CTIT.2018.8649512

Publication date:

2019

Document Version

Author accepted manuscript

Link to publication in ResearchOnline

Citation for published version (Harvard):

Stouraitis, V, Mior Harris, MH, Kyritsis, M \& Boonchoo, P 2019, A validation of web-based surveys for exploratory research in the areas of business and entrepreneurship. in 2018 Fifth HCT Information Technology Trends (ITT). IEEE, pp. 91-93. https://doi.org/10.1109/CTIT.2018.8649512

\section{General rights}

Copyright and moral rights for the publications made accessible in the public portal are retained by the authors and/or other copyright owners and it is a condition of accessing publications that users recognise and abide by the legal requirements associated with these rights.

Take down policy

If you believe that this document breaches copyright please view our takedown policy at https://edshare.gcu.ac.uk/id/eprint/5179 for details

of how to contact us. 


\section{A Validation of Web-based Surveys for Exploratory Research in the Areas of Business and Entrepreneurship}

\author{
Vassilios Stouraitis \\ Dept. of Food Studies \\ American University of Rome \\ Rome, Italy \\ v.stouraitis@aur.edu \\ Mior Harris Mior Harun \\ Dept. of International Business \\ Universiti Teknologi MARA \\ Shah Alam, Malaysia \\ miorharris@salam.uitm.edu.my
}

\author{
Markos Kyritsis \\ Dept. of Computer Information \\ Sciences \\ Higher Colleges of Technology \\ Sharjah, UAE \\ mkyritsis@hct.ac.ae
}

\author{
Pattana Boonchoo \\ Dept. of Marketing \\ Thammasat Business School \\ Bangkok, Thailand \\ pattana@tbs.tu.ac.th
}

\begin{abstract}
In this study, we demonstrate that web-based surveys are suitable for data collection in academic Businessrelated research. Using one of our datasets from an online study on entrepreneurial orientation, we investigated the construct validity and reliability of the instrument used to collect the data. Our analysis supports that for 28 Likert-scaled questionnaire items, a sample size of 332 people was adequate to conduct principle component analysis (PCA) and load the items into five components that are supported by literature. Cronbach's alpha was consistently high $(\alpha=0.92)$, with no evidence that the reliability would increase if any of the survey items were dropped. We therefore conclude that for short webbased surveys ( $<30$ items), a sample size of $>\mathbf{3 0 0}$ is suitable for exploratory factor analysis.
\end{abstract}

Keywords- Survey, Web-based, Principle Component Analysis, Validity, Reliability

\section{INTRODUCTION}

The use of web-based technology for data collection is becoming pervasive [5], particularly due to the prospects of lowering time and cost [12], simplifying data collection [3], as well as providing access to a large sample of potential participants [14]. Indeed, online surveys have been used by a plethora of studies from a diverse set of research areas [9][11][18].

Some studies have shown that online surveys are at least as reliable as mailed paper-based surveys [13], and more reliable than telephone surveys [2]. However, the lack of stringent controls commonly found in laboratory settings, have led authors to question the validity [1] and reliability of such tests; see [19] for a comprehensive review.

In the area of Business, surveys are a common data collection method for investigating perceptions and motivations of employees, customers, and managers (e.g., see [16][17]), but can often be tedious, particularly due to the large sample size required for the analysis of ordinal Likertscaled data. Case in point, even for a simple $\chi^{2}$ test on a $4 \times 4$ contingency table, power analysis indicates that 143 participants are required to achieve a statistical power of 0.8 ( $80 \%$ chance to find an effect when one exists, assuming a medium effect size).

Deciding on a sample size in order to conduct exploratory factor analysis is even more confusing. Authors cannot agree on the required sample size to correctly run a principle component analysis on questionnaire items, with recommendations ranging from 100 participants, all the way to 500 participants [6][7][10]. If we assume that the error variance due to the lack of experimental controls in an online study is higher, then these numbers are optimistic, and should probably be even higher.

In this paper we investigate the construct validity and reliability of an online survey that was constructed to collect attitudes on entrepreneurial orientation. Literature in the area allowed us to identify five main motivators ("Competitive aggressiveness", "Entrepreneurial motivations", "Negative externalities", "Job motivation", "Personal issues"), which were used to validate our questions. We examine the construct validity of our online survey by checking whether five components explain most of the variance when performing a principle component analysis on the data, and whether the survey items load well into their expected components. Finally, reliability was examined using Cronbach's alpha.

\section{METHOD}

\section{A. Participants}

We used a combination of convenience, snowball, and random sampling, to recruit 332 participants (164 females and 168 males) through email and social media. The level of education of the participants was high: $56 \%$ claimed to be university graduates, $33 \%$ claimed to have completed postgraduate studies, $6 \%$ stopped after high school, and the rest preferred not to answer. Our participants were asked to complete an online questionnaire. Personal information was not stored, nor were IPs logged or any other information that would otherwise allow us to identify participants. Emails are stored by the tool we used (Google Forms), but this information was immediately deleted when the data was downloaded as a csv file. Participants were not compensated for their time.

\section{B. Materials}

The questionnaire was created using Google Forms. Online surveys created using Google's toolkit consist of the usual HTML elements such as input boxes, radio buttons, drop down menus, etc., allowing our participants to respond to the 28 -point Likert-scaled questions by clicking on the radio button with a ranked score. The survey was made 
available to participants through a hyperlink that allowed them to access it through their browser.

\section{Procedure}

Participants were shown an information sheet and consent form at the start of the survey. Consent was required for the data to be used, and was provided by ticking the "agree to participate" checkbox. Data from any participant that did not tick that box was removed from the analysis.

\section{RESULTS}

\section{A. Assessing the Internal Consistency of the Items}

To test the reliability of our online survey, we used Cronbach's alpha, which reported that $\alpha=0.92$ (with the general consensus being that $\alpha>0.8$ is acceptable). Further analysis did not indicated that the reliability score would increase if we dropped any of the items. Therefore, the question items showed good internal consistency.

\section{B. Assessing the Construct Validity of the Survey}

Principle Component Analysis (PCA) with varimax rotation was used on the 28 Likert-scaled questions that measured attitudes towards entrepreneurship. The KaiserMeyer-Olkin (KMO) measure of sampling adequacy was 0.89 , which is well above the acceptable level for using PCA [8].

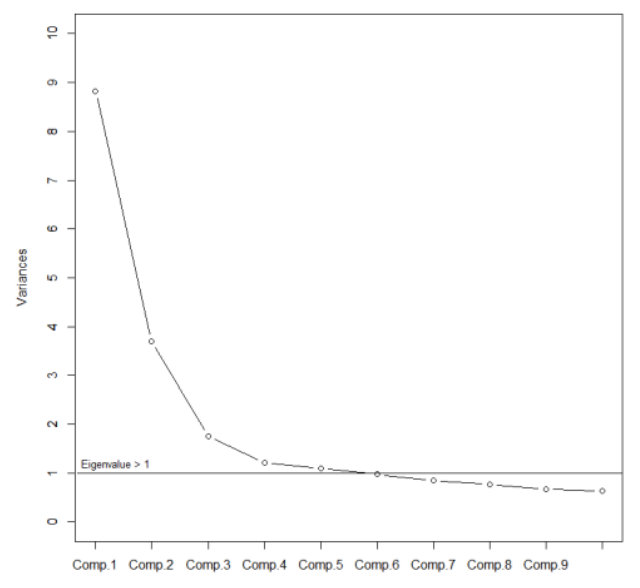

Fig. 1. Scree plot showing the variance explained by each component. Values $>1$ were used to determine the number of components

Kaiser's stopping rule states that components with eigenvalues (a measure of how much variance is explained by each component) above one should be included in the analysis, however, the scree plot (figure 1) shows an elbow at four components (i.e., most of the variance is explained by the first four components). In case of doubt, it is better practice to accept more components, rather than less, since overfactoring is preferred to underfactoring [4].
TABLE I. ITEM LOADINGS FOR FIVE COMPONENTS

\begin{tabular}{|l|c|c|}
\hline \multicolumn{3}{|c|}{ PCA Summary } \\
\hline \multicolumn{1}{|c|}{ Component Name } & $\begin{array}{c}\text { No. of } \\
\text { Items }\end{array}$ & Loadings \\
\hline Competitive aggressiveness & 9 & All $>0.69$ \\
\hline Entrepreneurial motivations & 7 & All $>0.5$ \\
\hline Negative externalities & 5 & All $>0.52$ \\
\hline Job motivation & 4 & All $>0.53$ \\
\hline Personal issues & 2 & All $>0.71$ \\
\hline
\end{tabular}

Items were loaded according to the criterion discussed by [15], i.e., with loadings $>|0.4|$. The number of loaded items can be seen in table 1. Unfortunately, some of the items did not load as expected, leaving component five with only two items. One solution would be to use four components (which is supported by the scree plot elbow technique), however the two items would not load well to the other components. Either way, the remaining components were loaded as expected with a decent number of items each.

\section{Discussion}

In the past, studies have often questioned the validity of online questionnaires for academic research, with some generally supporting their use [2][13], while others being more cautious [1]. The uncontrolled nature of these experiments, may lead to problems, particularly in exploratory research, where there are contradictions on the acceptable sample size when performing Principle Component Analysis (PCA) [6][7][10].

To evaluate the use of online surveys we used PCA on a dataset that was collected using Google Forms, and we validate the survey by investigating whether the items load on to their expected components (which were extracted from literature). Our results showed that, with the exception of component 5 ("Personal issues"), the components had a healthy number of items each, and were populated by the items that we predicted when developing the survey. The last component was only loaded with two items, which was unexpected, and is something we believe requires further evaluation. Nevertheless, since most items fit their predicted dimensions, the PCA itself had a good KMO, and all the items were reliable $(\alpha=0.92)$, we argue that for a 5-point Likert-scaled online survey, with $<30$ items, then a sample size of $>300$ is adequate for this type of research.

\section{REFERENCES}

[1] Braithwaite, D., Emery, J., De Lusignan, S., \& Sutton, S. (2003). Using the Internet to conduct surveys of health professionals: a valid alternative?. Family practice, 20(5), 545-551.

[2] Braunsberger, K., Wybenga, H., \& Gates, R. (2007). A comparison of reliability between telephone and web-based surveys. Journal of Business Research, 60(7), 758-764.

[3] Daley, E. M., McDermott, R. J., McCormack Brown, K. R., \& Kittleson, M. J. (2003). Conducting web-based survey research: a lesson in internet designs. American Journal of Health Behavior, 27(2), 116-124.

[4] Fabrigar, L. R., Wegener, D. T., MacCallum, R. C., and Strahan, E. J. (1999), "Evaluating the use of exploratory factor analysis in psychological research", Psychological Methods. 4(3) :272.

[5] Greenlaw, C., \& Brown-Welty, S. (2009). A comparison of webbased and paper-based survey methods: testing assumptions of survey mode and response cost. Evaluation review, 33(5), 464-480. 
[6] Gorsuch, R. L. (1983). Factor analysis Lawrence Erlbaum Associates. Hillsdale, NJ.

[7] Hutcheson, G. D., \& Sofroniou, N. (1999). The multivariate social scientist: Introductory statistics using generalized linear models. Sage.

[8] Kaiser. H.F. (1974). "An index of factor simplicity”. Psychometrika. 39 (1):31-36

[9] Lagan, B. M., Sinclair, M., \& George Kernohan, W. (2010). Internet use in pregnancy informs women' s decision making: a web - based survey. Birth, 37(2), 106-115

[10] Larry, P. H., \& Edward, J. (1994). A step-by-step approach to using the SAS system for univariate and multivariate statistics. Cary, NC: SAS Institute Inc.

[11] Lowe, A., \& Locke, J. (2005). Perceptions of journal quality and research paradigm: results of a web-based survey of British accounting academics. Accounting, Organizations and Society, 30(1), 81-98.

[12] Parks, K. A., Pardi, A. M., \& Bradizza, C. M. (2006). Collecting data on alcohol use and alcohol-related victimization: a comparison of telephone and Web-based survey methods. Journal of Studies on Alcohol, 67(2), 318-323.
[13] Ritter, P., Lorig, K., Laurent, D., \& Matthews, K. (2004). Internet versus mailed questionnaires: a randomized comparison. Journal of Medical Internet Research, 6(3).

[14] Sills, S. J., \& Song, C. (2002). Innovations in survey research: An application of web-based surveys. Social science computer review, 20(1), 22-30.

[15] Stevens, J. (2002). Applied Multivariate Statistics for the Social Sciences. 4th ed. Lawrence Erlbaum Associates, Mahwah, NJ.

[16] Stouraitis, V., and Kyritsis, M., (2016). Small and medium-sized enterprises' exporting: home and host country motivators effect on first and successive export venture decision. Journal of contemporary management issues, 21(1), 97-115.

[17] Stouraitis, V., Mior H.M. \& Kyritsis, M. (2017). Motivators of SME initial export choice and the European Union regional effect in manufacturing. International Journal of Entrepreneurial Behavior \& Research, 23(1), 35-55.

[18] Wong, J. G., Cheung, E. P., Chan, K. K., Ma, K. K., \& Wa Tang, S. (2006). Web-based survey of depression, anxiety and stress in firstyear tertiary education students in Hong Kong. Australian \& New Zealand Journal of Psychiatry, 40(9), 777-782.

[19] Wyatt, J. C. (2000). When to use web-based surveys. 